\title{
Internal migration related factors among dengue patients in Western Province, Sri Lanka
}

\author{
Sharika Peiris ${ }^{1}$, Indrakantha P Welgama ${ }^{2 *}$, Kolitha Wickramage ${ }^{3}$, Chrishantha Abeysena ${ }^{4}$ \\ ${ }^{1}$ International Organization for Migration, Sri Lanka; ${ }^{2}$ Ministry of Health, Sri Lanka; ${ }^{3}$ International Organization \\ for Migration, Switzerland; ${ }^{4}$ Department of Public Health, Faculty of Medicine, University of Kelaniya, \\ Sri Lanka. \\ *Correspondence: ip2000k@gmail.com (iD https://orcid.org/0000-0003-1194-3082 \\ DOI: https://doi.org/10.4038/jccpsl.v25i2.8181
}

Received on: 10 October 2018

Accepted on: 29 May 2019

\begin{abstract}
Introduction: In recent years, Sri Lanka has experienced a surge in the incidence of dengue. Among other reasons, internal migration of people into dengue-high risk areas is thought to be an important factor for the rising case load.

Objectives: To identify the factors associated with internal migration of low-income adults among dengue patients in Western Province, Sri Lanka

Methods: This was a descriptive cross-sectional study conducted in the Western Province in November 2017. The study population consisted of 473 confirmed adult dengue patients. Internal migrant was defined as an adult who has moved from his original place of residence and been living in the district migrated to for less than five years. A pre-tested interviewer-administered questionnaire was used for data collection.

Results: There were $53(11.2 \%)$ internal migrants belonging to low-income group among the dengue patients. Of them, $30(56.6 \%)$ stated that the reason for migration was employment while $9(17 \%)$ indicated education. Being of age $\leq 30$ years, coupled with low educational level showed a statistically significant association with internal migration of adults having dengue fever. Although there were more males than females, and more displaced than non-displaced among the internal migrants, these were not statistically significant.

Conclusions: Younger age and low educational level were associated with internal migration mainly due to employment.
\end{abstract}

Key words: dengue, dengue virus, factors, migration, outbreak 


\section{Introduction}

Sri Lanka usually experiences dengue outbreaks twice per year, and the last outbreak in May 2017 was the worst ever in its history, causing over 300 deaths in the island. Till September, 151,820 suspected dengue cases have been reported to the Epidemiology Unit of the Ministry of Health from all parts of the island. Approximately $43.49 \%$ of these dengue cases had been reported from the Western Province (1).

Human movement, also known as migration, in a country can be outbound, inbound and internal. Most of the internal migrants of Sri Lanka are thought to be those who have migrated from their original rural areas to modern urban areas, for different reasons including education and employment. Temporary migration for the purpose of employment is frequently noted especially in the Western Province of Sri Lanka, where a large number of people from other parts of the country are engaged in various types of employment, mostly with temporary accommodation in rooms, unconducive accommodation facilities and construction sites (2). Due to this reason, these migrants may be more at risk of contracting dengue, which is highly prevalent in Western Province, when compared with their original residences. Also, the migration status of the patients from dengue non-endemic areas to endemic areas is thought to be a risk factor, of which the epidemiology is poorly understood. Research evidence suggests that internal migrant workers are more vulnerable to dengue (3-5). However, the underlying determinants for their vulnerability to dengue has not been explored in depth. Although poor living conditions have been identified as an independent risk factor for dengue, whether it is the same risk that makes internal migrant workers (especially those of low economic status) more vulnerable to dengue is not conclusive. The objective of this study was to identify the internal migration related factors among dengue patients in the Western Province. The study results are expected to be of use to the Epidemiology Unit in identifying strategies for the prevention of increased transmission of dengue in migrants.

\section{Methods}

A cross-sectional descriptive study was conducted in the Western Province, which consists of Colombo, Kalutara and Gampaha Districts. The period of study was from November to December 2017. The study population consisted of patients aged 18-64 years diagnosed with dengue, which has been confirmed and entered in infectious disease registers maintained at the respective medical officer of health $(\mathrm{MOH})$ area. Patients with mental disabilities who are unable to comprehend and answer the questions on their own were excluded from the study. This was one component of a study conducted among 473 dengue patients, and therefore the sample size determination was not done for the purpose of this study. Patients were recruited from all three districts in the Western Province. Within each district, four $\mathrm{MOH}$ areas were selected randomly, from which patients were randomly selected using the infectious disease register.

A pre-tested interviewer-administered questionnaire was used for data collection. Twelve pre-intern medical officers were selected for this purpose and were provided with thorough training on data collection, prior to visiting the houses of patients selected for the study. Internal migrant of low economic status was defined as an adult who has been living in the district for less than five years. The low-economic group was defined as those whose monthly income is below the national median income of Rs. 16,667 (6). Ethics clearance was granted by the Ethics Review Committee of the Faculty of Medicine, University of Kelaniya, Sri Lanka.

All data were entered into an MS Excel data sheet while Statistical Package for Social Sciences (SPSS) was used for data analysis. Data were reported as mean, standard deviation (SD) and median for continuous variables and percentages for categorical variables. We used Chi-squared test with probability less than 0.05 considered as significant in relation to the assessment of associations.

\section{Results}

A total of 473 patients were recruited. The mean age was $36.6(\mathrm{SD}=13)$ years. The percentages of male and female patients were $48.6 \%(\mathrm{n}=230)$ and $51.4 \%$ $(\mathrm{n}=243)$, respectively. There were $53(11.2 \%)$ internal migrants of low economic status among the dengue patients. Of them, $30(56.6 \%)$ stated that the reason for migration was employment while $9(17 \%)$ indicated education. The majority $(48 \%, \mathrm{n}=227)$ worked for private institutions, whereas $10.4 \%(\mathrm{n}=49)$ worked for government institutions and $5.3 \%(\mathrm{n}=25)$ were not 
employed. Of the total sample, $94.9 \%(\mathrm{n}=449)$ resided in their own/ rented house, $3.4 \%(\mathrm{n}=16)$ in a boarding place and $1.5 \%(\mathrm{n}=7)$ in a construction site. Among the patients who resided in a boarding place or construction site, $78.3 \%(\mathrm{n}=18)$ were internal migrants. Only $12 \%(n=57)$ of the patients were affected by floods in the recent past before getting the disease. Of the 473 patients, 3.8\% $(\mathrm{n}=18)$ had been displaced due to floods. The median duration of displacement was 8 days (range $=1-18$ days).
Bivariate analysis results showed that most of the patients who had internally migrated belonged to the age group of $\leq 30$ years compared to non-migrants, which was statistically significant (Table 1). Multivariate analysis results showed that internal migration had a positive association with age $\leq 30$ years and low educational level. There was a higher proportion of males than females and displaced than non-displaced persons among the internal migrants, which were not statistically significant (Table 2).

Table 1. Association between socio-demographic characteristics and internal migration among dengue patients

\begin{tabular}{|c|c|c|c|c|}
\hline \multirow[t]{2}{*}{ Characteristics } & \multicolumn{3}{|c|}{ Internal migrants, No. (\%) } & \multirow[t]{2}{*}{ p value } \\
\hline & $\begin{array}{c}\text { Yes } \\
(\mathbf{n}=53)\end{array}$ & $\begin{array}{c}\text { No } \\
(n=420)\end{array}$ & $\begin{array}{c}\text { Total } \\
(\mathrm{N}=\mathbf{4 7 3})\end{array}$ & \\
\hline \multicolumn{5}{|l|}{$\operatorname{Sex}$} \\
\hline Male & $32(13.9)$ & $198(86.1)$ & 230 & 0.07 \\
\hline Female & $21(8.6)$ & $222(91.4)$ & 243 & \\
\hline \multicolumn{5}{|l|}{ Age } \\
\hline$\leq 30$ years & $29(15.9)$ & $153(84.1)$ & 182 & 0.01 \\
\hline$>30$ years & $24(8.3)$ & $265(91.7)$ & 289 & \\
\hline \multicolumn{5}{|l|}{ Educational level } \\
\hline $\mathrm{Up}$ to $\mathrm{O} /$ Levels & $21(15.3)$ & $116(84.7)$ & 137 & 0.07 \\
\hline$>\mathrm{O} /$ Levels & $32(9.5)$ & $304(90.5)$ & 336 & \\
\hline \multicolumn{5}{|l|}{ Income* } \\
\hline Low & $15(6.6)$ & $211(93.4)$ & 226 & 0.06 \\
\hline High & $18(13.0)$ & $120(87.0)$ & 138 & \\
\hline \multicolumn{5}{|c|}{ Less-skilled worker } \\
\hline Yes & $12(13.2)$ & $79(86.8)$ & 91 & 0.44 \\
\hline No & $38(10.5)$ & $328(89.6)$ & 366 & \\
\hline \multicolumn{5}{|c|}{ Flood affected area } \\
\hline Yes & $6(10.5)$ & $51(89.5)$ & 57 & 0.9 \\
\hline No & $46(11.1)$ & $369(88.9)$ & 415 & \\
\hline \multicolumn{5}{|l|}{ Displaced } \\
\hline Yes & $3(16.7)$ & $15(83.3)$ & 18 & 0.45 \\
\hline No & $50(11.1)$ & $405(89.0)$ & 455 & \\
\hline
\end{tabular}

${ }^{*}$ Fisher's Exact Test 
Table 2. Factors associated with internal migration by multiple logistic regression analysis

\begin{tabular}{lcccccc}
\hline Factors & B & SE & OR & 95\% CI & p value \\
\hline Age $\leq$ 30 years & 0.76 & 0.31 & 2.14 & 1.17 & 3.91 & 0.01 \\
Education up to O/ Level & 0.66 & 0.31 & 1.93 & 1.05 & 3.53 & 0.03 \\
Male sex & 0.40 & 0.31 & 1.50 & 0.82 & 2.73 & 0.19 \\
Displaced & 0.80 & 0.67 & 2.23 & 0.60 & 8.34 & 0.23 \\
\hline
\end{tabular}

$\mathrm{B}=$ Beta regression coefficient; $\mathrm{SE}=$ standard error

\section{Discussion}

We found that age and low educational level were independently associated with internal migration of the patients diagnosed of dengue.

Among the patients who resided in a boarding place or construction site, $78.3 \%$ were internal migrants. The study shows that they have a higher risk of exposure to dengue virus. We could not find any studies done on factors associated with internal migration among dengue patients from other studies. Although there is evidence that migrant workers had more risk of dengue (3-5), probably due to residing in poor housing conditions. Therefore, a comparative study would be recommended for assessing the association between risks of dengue infection and residing in poor housing conditions.

A major limitation of this study was high nonresponse rate. As we invited 650 dengue patients, only 473 patients participated in the study, with the response rate of $73 \%$. This may affect the generalizability of the finding.

\section{Conclusion}

In conclusion, being 30 years of age or younger and having a low educational level imparted a significant risk for dengue compared to non-migrants. were associated with internal migration mainly due to employment.

\section{Author Declarations}

Competing interests: The authors declare that they have no competing interests.
Ethics approval and consent to participate: The ethics clearance was granted by the Ethics Review Committee of the Faculty of Medicine, University of Kelaniya (Ref No: $P / 271 / 11 / 2017)$ and the consent was obtained prior to data collection. Permission was obtained from the Director General of Health Services of the Ministry of Health, the Provincial Director of Health Services (Western Province), the relevant district regional medical officers and respective MOH's prior to the conduct of the study.

Funding: The study was funded by the Canadian Government and was implemented by the International Organization for Migration.

Acknowledgements: We would like to thank all the participants of the study, data collectors, the Canadian Government for providing required funds, IOM for facilitating the implementation of the study and authorities of the Ministry of Health Sri Lanka for providing necessary approval.

Author contributions: SP contributed to the conception and design, data acquisition, analysis and interpretation, drafting and revising the article for intellectual content and final approval; IW participated in the study design, coordinated the data collection, reviewed and edited the final manuscript; $\mathrm{KW}$ reviewed and edited the final manuscript; CA participated in the design, performed the statistical analysis, interpreted the data and drafted the first version of the manuscript. All authors read and approved the final manuscript.

\section{References}

1. Epidemiology Unit. Distribution of notification (H399) dengue cases by month. Colombo: Ministry of Health, Sri Lanka, 2019. 
2. Department of Census and Statistics. Internal and International Migration Patterns. Report of the National Population and Housing Census 2012. Colombo: Ministry of Policy Planning Economic Affairs, 2012.

3. Tsuzuki A, Duoc V, Sunahara T, Suzuki M, Nguyen H, et al. Possible association between recent migration and hospitalisation for dengue in an urban population: a prospective case-control study in Northern Vietnam. Tropical Biomedicine 2014; 31(4): 698-708.

4. Rabaa MA, Klungthong C, Yoon I-K, Holmes EC, Chinnawirotpisan $\mathrm{P}$, et al. Frequent in-migration and highly focal transmission of dengue viruses among children in Kamphaeng Phet, Thailand. PLoS Neglected Tropical Diseases 2013; 7(1): e1990.

5. Lugo B. Correlation analysis of climatic variables, migration and dengue cases in South East Florida. Dr PH Dissertation. Minnesota: Walden University, 2015.

6. Department of Census and Statistics. Final Report of Household Income and Expenditure Survey 2012/ 2013. Colombo: Ministry of Policy Planning Economic Affairs, Child Youth and Cultural Affairs Sri Lanka, 2015. 